\title{
Chapter 2: The Governance of Cooperative Banks: Main features and new challenges
}

\author{
Prof. Eric Lamarque \\ IAE Paris - Sorbonne Business School \\ Chair of "Management and Governance of Financial Cooperatives" - GREGOR
}

When you ask a member of any cooperative bank what it is that makes the model unique, the immediate answer is: "governance". Members are the cooperative owners. Each member has one voting right, independent of amount of money invested in membership shares, a model of democracy according to all supporters of the model. But only a small group of activist members is actually aware of their ability to participate in management control at the various decision-making levels. Others are not so engaged. Some don't even remember that they own these membership shares, while most are just concerned about return on investment... because this is often how these particular shares are proposed to customers.

After the tarnished reputations of the banking crisis, cooperative banks rediscovered that the main "asset" they could use to differentiate themselves from traditional, shareholder-owned banks was membership. Members need to become more aware of their right to participate in the decisionmaking process. We will expand upon the main part of this process first and explain how and at which level customers are involved in the governance structure. Speaking about governance means analyzing how decisions are made and managers controlled by members at the various decisionmaking levels. Next, identifying the main feature of the model allows us to present the various models of governance in the context of cooperative banks. There is not a single model, but a range of structures. The models must first be understood before looking at how key decisions are managed. In the third point of the chapter we focus on risk appetite definition, which is now a key issue for cooperative bank boards. The responsibility of boards and board members is clearly involved in the new regulatory context. This new regulatory context (described in chapter 5) also concerns governance aspects. Cooperative banks view the Basel III requirements and consequences for the governance model as an attack with a risk of losing their specificity. The main issue here is perhaps to put forward proposals for preserving the model, rather than trying to convince regulators and supervisors to change their mind!

The present chapter is based on the results of several studies conducted over the past five years in the Sorbonne Business School research lab (Chair of "Management and Governance of Financial Cooperatives", Paris 1 Pantheon Sorbonne University). During this time, we have highlighted the model's main characteristics, how decisions are made, how risk is managed, and how new regulations impact the structures. Governance is thus one of the primary topics of our research program. Our contributions have been recognized both from our participation in world summits on cooperatives, and as guests at many cooperative discussion groups with senior management and members on transforming the governance model while maintaining the fundamental values and principles which have existed for 200 years. 


\subsection{Features of the cooperative banking model of governance}

Cooperative banks share principles that set them apart and distinguish them from other banks. Four principles have been identified as standing out as particularly important (Deville and Lamarque, 2014). However, it is important to remember that they are often implemented differently from one cooperative bank to another, thus contributing to the sector's diversity.

\section{- Unique practices for allocating earnings}

Customers can join cooperative banks as members. Each member is entitled to a vote regardless of their equity share or how much they hold in deposits and loans. At general meetings, members play a role similar to that of stockholders by voting to determine the returns paid on membership shares and evaluating the performance of general managers at the local or regional levels. There are significant differences between these and traditional shareholder assemblies due to the "one member, one vote" principle. A long-term vision based on social engagement takes precedence over short-term financial needs. This is the first effect of the democratic principle. One consequence is that a large proportion of the results remain within the cooperative.

\section{- Autonomy}

Autonomy is an important principle that goes hand in hand with democracy. It appears to be a concept better adapted in a decentralized structure. Some local branches appear to enjoy real autonomy. Beyond these statements, there is a real sense of discretionary management. Local and regional managers are quick to mention that the role and importance of local boards constitute an asset compared to traditional banks. To offset the autonomy that local branches enjoy, a situation rooted in the historical philosophy of the cooperative movement, the national and regional levels implement tools to foster a common strategic alignment. Information and IT systems are often employed for this purpose. The autonomy that general managers have at the local and regional level varies depending on the degree of oversight provided by the next level up, but also by elected members.

This autonomy aside, certain national levels attempt to influence decision-making or at least coordinate the actions of local entities in such strategic areas as marketing and product offerings, recruitment policy, and risk.

Lastly, autonomy also depends on the types of oversight employed. The principle of autonomy and the freedom of management that comes with it give rise to another principle: accountability. Cooperative employees, managers, and general managers who enjoy real decision-making authority feel genuinely accountable for their results.

\section{- Accountability}

The principle of accountability applies to cooperatives' relationships with both their customers and their employees/managers. Firstly, where customers and members are concerned, accountability is exercised by listening, providing support, and cultivating relationships. On several occasions during the interviews, subjects stressed the important role general managers played in the community, including serving as president of an association (in a few cases). The role was described as a way to build relationships and get to know the customers and members who participate in the activities. But 
it was not without controversy: local managers are subject to market constraints as well as productivity and profitability requirements, and they demand a degree of decision-making authority that they feel is legitimate due to their crucial role in developing customer/member relationships.

Where staff are concerned, accountability translates into low layoff rates (particularly during the crisis), high training rates, and the possibility of internal promotion. A particular profile is favored. When it comes to managing employees, decision-making authority comes up regularly.

\section{- Compensation policy and incentive}

Recognition and financial incentives are not tied to results. Bonuses do exist, but they are only paid once the fiscal year is over and are subject to limitations. However, internal promotion is common. Elected officers do not receive direct compensation and tend to perform their work on a volunteer basis. Their primary incentives are the autonomy and freedom to make decisions (within limits) at the operational level. Customer contributions as members are valued. Recognition is most apparent in the decision-making authority extended to everyone from customer service representatives to branch managers. Employees appreciate this freedom and feel that it gives meaning to their work.

In addition to these main features considered as the basic values associated with cooperative banks and influencing the decision model, we must add another dimension which characterizes each coop: their territorial entrenchment. Coop Banks have various ways of organizing their structure: according to size, to the territory they cover but also their history. We identify three levels of decision-making:

- Local: sometimes it is only one branch or a small number of branches in a town or city district. Local customers become local members. The range of decisions upon which they have influence is small but is the starting point for constituting boards locally, regionally and nationally from the general assembly of local members.

- Regional: some banks have full autonomy to make decisions at regional levels. Depending on the size of the branch network, and following successive mergers between smaller coops, some groups maintain a powerful regional level. Others, on the other hand, have no regional decision-making levels.

- National: pressured by regulations but also for purposes of internal transformation in order to better control certain decisions and provide greater coherence in the activity of the overarching level, big cooperative groups have centralized many decisions.

Not all cooperative banks have all three decision-making levels. Some do not have a local level, only regional and national; others do not have the regional, only local and national.

When describing the governance structure, we often use the term inverse pyramid. The local chairman of the board becomes a member of the board of the regional structure. And the chairman of the board at the regional level could be elected to the board of the national body. Ultimately, any local member could become the chairman of the board of a big cooperative bank with thousands of employees.

Local entrenchment is a specific feature of cooperative banks, and recognized as guaranteeing proximity to the needs and concerns of members who are also customers. The magnetic effect of 
territory on members or collectively is a key factor for each coop and probably one of differentiation if staff and managers show proper process, professionalism and that they care for members.

\subsection{Models of governance in Europe}

In recent years, very few descriptive studies have been conducted on the organizational structures of financial cooperatives. One example is the work of J. Birchall on co-operative businesses in the UK (2017) evaluating governance models in several industries including banking. It raises a number of issues and describes the mode of operation of several banks that we also analyzed in our research program. Again, working on the cases studied was essentially descriptive.

Most of the studies analyzing the organization and the governance structure use three criteria:

- Identifying levels of decision-making within cooperative groups

To characterize the various governance models in Europe, the first criterion is the number of decision-making levels we described earlier. Different combinations of these levels provide an initial picture of the diversity of coop governance models: local/regional/national, local/national and regional/national. Also worthy of note is that coops in some countries may be only local or regional. Further, depending on size of the European country or territory, distinguishing local and regional is not always easy. A methodology for analyzing this diversity of governance model was proposed in Deville and Lamarque, 2014. This section summarizes the results of a study presented to the second world cooperative summit in Québec, 2014.

It is important to evaluate the reality of the decision-making power at each level when considering the number of decision-making levels. Figure 2-1 gives an initial analysis:

Figure 2-1: Power of decision at different level of governance

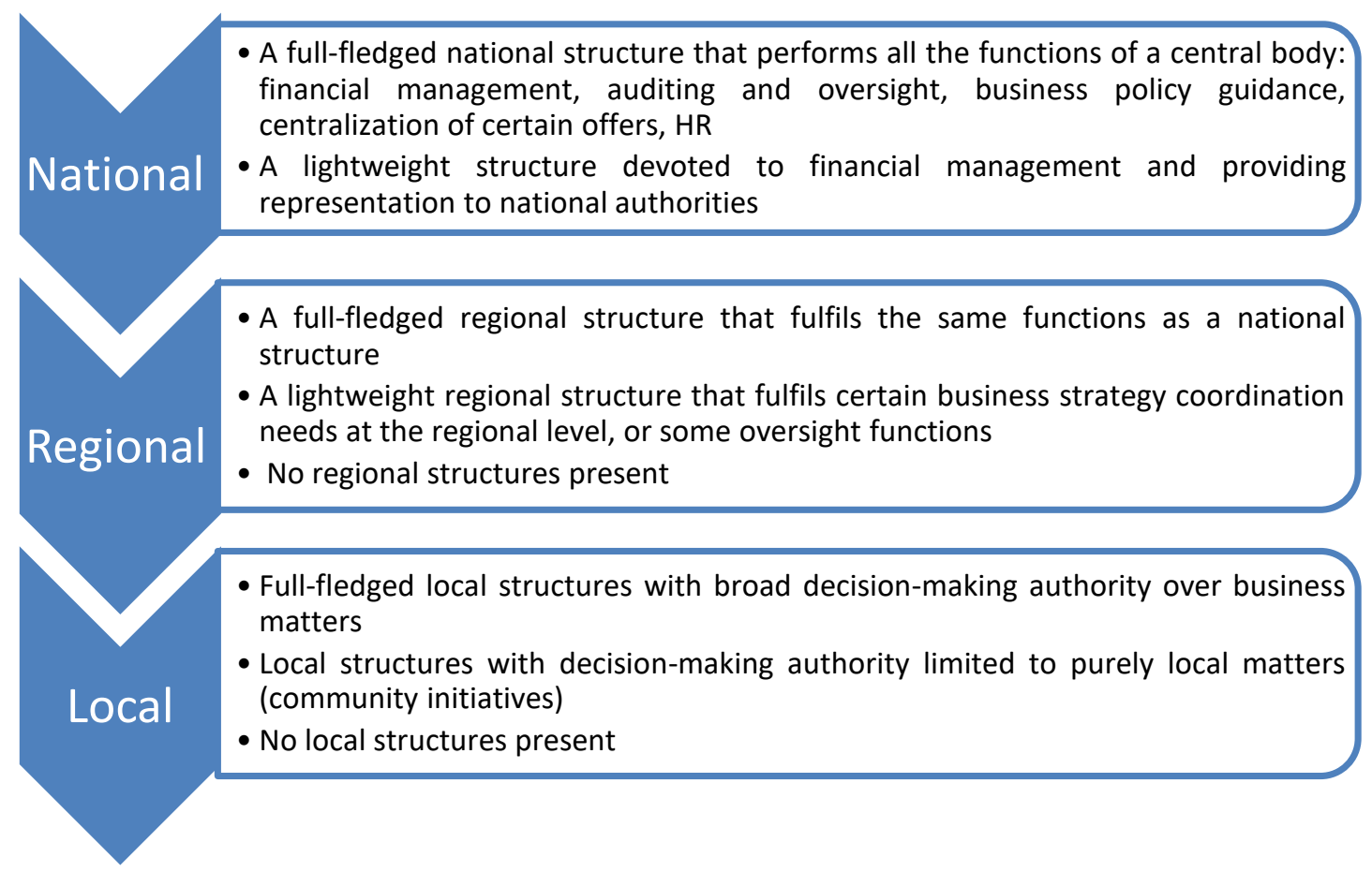

Member 
This first criterion allows for an initial understanding as to how cooperative groups are managed. A more detailed analysis allows us to understand the situations in which the relevant level has a limited or a strong influence on decisions (table 2-1).

\section{Table 2-1: Distribution of decision-making authority between levels}

\begin{tabular}{|c|c|c|}
\hline & Limited influence & Significant influence \\
\hline $\begin{array}{l}\text { National } \\
\text { structure }\end{array}$ & $\begin{array}{l}\text { - Only handles oversight of } \\
\text { group entities } \\
\text { - Organizes the group's } \\
\text { solidarity system } \\
\text { - Manages liquidity on } \\
\text { behalf of branches }\end{array}$ & $\begin{array}{l}\text { In addition to oversight, and guaranteeing and } \\
\text { managing liquidity: } \\
\text { - Defines marketing policy and business objectives } \\
\text { for all entities } \\
\text { - Names executive managers of regional and local } \\
\text { entities and determines the variable share of their } \\
\text { compensation } \\
\text { - Allocates financial resources to different entities } \\
\text { and has full control over investment policy }\end{array}$ \\
\hline $\begin{array}{l}\text { Regional or } \\
\text { local structure }\end{array}$ & $\begin{array}{l}\text { Cannot make any decisions } \\
\text { without approval or if } \\
\text { outside the framework } \\
\text { established by the national } \\
\text { entity }\end{array}$ & $\begin{array}{l}\text { The structure: } \\
\text { - Defines marketing policy and business objectives } \\
\text { for all entities } \\
\text { - Names executive managers of regional and local } \\
\text { entities and determines the variable share of their } \\
\text { compensation } \\
\text { - Allocates financial resources to different entities } \\
\text { and has full control over the investment policy }\end{array}$ \\
\hline
\end{tabular}

Source: Deville and Lamarque, 2015

However, to further understand the decision process, two more criteria are needed:

- Analyzing interactions between the levels in terms of both management and boards

- Examining relationships of influence between boards themselves and management structures themselves.

For this it is necessary to identify the type of decision taken at each level: marketing, communication, credit, HR, finance and risk, control (see table 2-2).

If a level can act only in one area, such as oversight and financial matters, its authority is limited. If, on the contrary, it makes all management decisions, its authority is significant. The nature of interactions depends also on the degree of real autonomy of regional and local entities vs. national structures for these decisions. 
Table 2-2: Type and subject of the decisions observed*

\begin{tabular}{|c|c|c|c|c|}
\hline & Control & HR & Finance & $\begin{array}{l}\text { Marketing } \\
\text { and customer } \\
\text { relations } \\
\text { management }\end{array}$ \\
\hline $\begin{array}{l}\text { Decisions } \\
\text { observed }\end{array}$ & $\begin{array}{l}\text { - Formal oversight by a } \\
\text { higher authority (audit, } \\
\text { inspection) } \\
\text { - Oversight by same-level } \\
\text { authorities } \\
\text { - Reporting to superior } \\
\text { levels or other entities } \\
\text { from the same level } \\
\text { - Comprehensive } \\
\text { performance evaluation } \\
\text { (customer satisfaction, } \\
\text { profitability, productivity, } \\
\text { employee turnover) } \\
\text { - Existence of benchmarking } \\
\text { between local or regional } \\
\text { entities }\end{array}$ & $\begin{array}{l}\text { - Recruitment of } \\
\text { mid-level } \\
\text { managers and } \\
\text { employees } \\
\text { - Recruitment of } \\
\text { senior managers } \\
\text { - Financial } \\
\text { incentives and } \\
\text { bonuses } \\
\text { - Disciplinary } \\
\text { actions } \\
\text { - Definition of } \\
\text { individual and } \\
\text { group objectives } \\
\text { - Training } \\
\text { leadership }\end{array}$ & $\begin{array}{l}\text { - Credit risk } \\
\text { decisions } \\
\text { - Liquidity } \\
\text { management } \\
\text { - Investment } \\
\text { decisions }\end{array}$ & $\begin{array}{l}\text { - Creation of } \\
\text { marketing } \\
\text { plan } \\
\text { - Business } \\
\text { decisions } \\
\text { (product } \\
\text { marketing) } \\
\text { - Monitoring } \\
\text { customer and } \\
\text { member } \\
\text { relations }\end{array}$ \\
\hline
\end{tabular}

* Risk policy will be analyzed separately

We mention this because, even if some local or regional entities have full autonomy from a legal point of view, things are actually more nuanced. The central body has a large number of employees and performs a certain number of functions for regional entities; it also tends to exercise considerable influence. As a result, decision-making authority that looks significant-and is often described as such by those involved-may in fact be quite limited. Local and regional entities that choose to truly exercise their decision-making autonomy may only do so if their results are solid enough to support them. This trend among cooperative groups toward centralization and alignment with national structures was visible in a number of countries, including France (J.N. Ory et al. 2006) through the 2000s. Evaluating the degree of centralization/decentralization in decision-making is not easy when you are an outsider but it is a key issue to understand the decision process.

- Weight and influence of governance structures on management decisions.

The third criterion to potentially affect each level is the capacity of governance bodies (general assembly and boards) to influence management decisions, a subject of recurring debate in the cooperative sector. The principle of autonomy was reinforced by the capacity of governance structures to provide adequate oversight and supervision for managers. Consensus holds that, beyond the oversight provided by governance and supervisory bodies to ensure members' interests are upheld, their influence is relatively weak. Members are elected more for purposes of political representation than for their skillsets or knowledge of how banks are managed and are thus unable to seriously challenge management decisions. This is undoubtedly why some cooperatives have strayed from their roots into the territory of financial markets and traditional banks, leaving their board members poorly equipped to ensure oversight. 
Recently, however, we note the growing impact of boards on a number of management decisions. This increased influence is clearly expected from banking-sector regulators, who want governance structures to not only exercise oversight, but also provide real contributions on major decisions and play an increasingly active role in risk policy. The gap in expertise between the two has led elected members to defer to managers and avoid too much direct involvement in management decisions. But observations have also shown that when elected board members have extensive management experience, they exert a far higher level of influence over managers.

Using these three criteria to analyze a number of cases in the European and Canadian cooperative bank sectors, we identified three models of governance. Our proposal does not claim to cover all models, although undoubtedly a large majority. Nevertheless, this three-level typology is still helpful in explaining the overall decision-making processes of cooperative structures.

But our analysis shows that decision-making influence is not always clearly divided between the levels and that final decisions are often the fruit of negotiations and compromises that increase the amount of time needed to make them. This phenomenon was observed in HR and marketing decisions. For example, looking at the implementation of a new approach to customer-relation management, collaboration between the central, local, and regional levels was observed in a number of cases. Customer-relation issues are often addressed by forming working groups made up of branch managers and national representatives tasked with supporting branch development. Representatives from national levels facing the same issues also participate in these groups. The preferred approach is to develop an action plan together for presentation to a decision-making authority with representatives from all levels of the organization.

The advantage of this approach is that no single entity can impose its vision on the group as a whole. Proposals are structured to appeal to all branches, and the working groups avoid designating a single orientation for the cooperative group as a whole. Though national entities have an understandable preference for standardized practices, local and regional entities tend to argue that the unique qualities of their environments justify deviating from national proposals.

Many feel that these working groups spend a great deal of time trying to find acceptable solutions that appeal to all branches, while only a handful end up fully embracing the national framework proposed. That said, national authorities do understand the futility of trying to impose uniform practices on branches accustomed to a certain degree of autonomy. A great deal of diplomacy is necessary to standardize general practices. At this level, the challenges encountered by cooperative banks are not so different from those facing major multinationals serving a variety of markets, customers and countries. They are also seeking a common set of business practices and guidelines for interacting with customers/members that allow them to develop a unique identity. For cooperatives, the values inherent to their cooperative status will obviously play a key role in informing on these common practices.

On other subjects, like oversight and financial matters, the division between the levels is much clearer.

Based on our research so far, I have identified three main models of governance in the cases I was able to study. Table 2-3 summarizes their main characteristics. 
Table 2-3: Cooperative bank governance models

\begin{tabular}{|c|c|}
\hline $\begin{array}{l}\text { Centralized } \\
\text { governance model }\end{array}$ & $\begin{array}{l}\text { A central entity that strongly influences decision-making and is able to exert its } \\
\text { authority across all levels and over all key group functions (marketing, HR, finance, } \\
\text { oversight). } \\
\text { In this model, elected members, general assemblies and boards provide assistance in } \\
\text { and backing for management decisions made at the regional and local levels. }\end{array}$ \\
\hline $\begin{array}{l}\text { Shared decision- } \\
\text { making model }\end{array}$ & $\begin{array}{l}\text { In this model, decision-making authority appears to be relatively significant at both } \\
\text { the national and regional levels. It is a harder model to pin down given that the } \\
\text { distribution of decision-making between levels tends to vary from one period to the } \\
\text { next. Decisions are often built in common. This model seems to have been more } \\
\text { centralized prior to the recession. In recent years regional entities have increased } \\
\text { their level of influence on group decisions. } \\
\text { Elected assemblies are consulted at the regional and local levels but do not set } \\
\text { objectives. }\end{array}$ \\
\hline $\begin{array}{l}\text { Decentralized } \\
\text { governance model }\end{array}$ & $\begin{array}{l}\text { Local and regional entities have significant authority over all key functions. The } \\
\text { central body's job is to monitor the performance of local entities, centralize financial } \\
\text { data, support implementation of development strategies, and manage liquidity. } \\
\text { This model can be broken down into two types, with decision-making authority } \\
\text { being concentrated at either the local (large number of small entities) or regional } \\
\text { (limited number of regional entities) level. } \\
\text { Elected assemblies at the regional and local levels are consulted and may participate } \\
\text { in making strategic decisions and defining objectives. }\end{array}$ \\
\hline
\end{tabular}

Source: Deville and Lamarque, 2015

This analytical framework is original and differs from those using legal categories to differentiate between decision-making bodies (such as Di Salvo, 2002). To apply it, we must first analyze decisionmaking categories more closely and determine how decision-making rights are distributed among the levels.

\subsection{Cooperative banks and risk appetite}

The cooperative banks' governance model differs according to nature of the decisions. Some decisions could be made at local or regional levels definitively without national levels being involved. Other decisions, specifically risk decisions, are largely decided at the national level with minor adaptation to local context. This topic is highly regulated and the main tendency is to centralize the methods and the level of risk that each entity will accept. Chapter 5 presents the various categories of risk a bank has to put under supervision by its own governance, and the process of decision concerning risk appetite must be clearly defined by the bank and identified by supervisors. The latter are worried about the decentralization of decision-making and extensive autonomy of local levels and have been pushing to centralize this kind of decision for many years. The national level plays a key role in this area and has to keep a complex equilibrium between legal requirements and the ongoing business of branches which make decisions on credit allowance, for example, a symbol of proximity in a cooperative bank. 


\subsection{1 - The specific place of risk governance in banking}

More and more discussion revolves around risk governance in banks, revealing it to be not just a job for certain experts in risks analysis and mitigation but a global system and culture of risk management that banks must develop. The governance body, board and risk committee on the board must produce a risk appetite framework and define a system of alert with respect to the measures to be taken in case of financial distress.

The regulation confers a number of powers on the central organization that flow directly from what the directive indicates and is expressed in each national regulation:

- To take all necessary steps to ensure the liquidity of the group as well as that of each of its networks and affiliates and to that effect determine the group's rules of liquidity management, particularly in defining the principles and modalities of the situation and direction of the financial management of its constituent entities, and the conditions in which the establishments may carry out operations with other credit institutions or investment companies, conduct securitization operations, issue financial instruments, or conduct any operation necessary for the management of liquidity.

- To take all necessary steps to ensure group solvency, especially by implementing mechanisms for internal group solidarity, and in creating a common guarantee fund and determining its rules of operation, modalities of intervening in supplementary funds, and the contributions of affiliated institutions for its provision and reconstitution within the context of each national regulation.

- To determine the principles and organizational conditions of an internal control mechanism for the group and each of its networks to ensure control of the organization, management and quality of the financial situation of affiliated establishments, particularly by means of on-site controls by, for example, general inspection.

- To determine the policy and principles for risk management as well as the limits for the group and each of its networks and ensure permanent oversight on a consolidated basis.

This predominance of the central level has a clear effect on risk policy and management. In general, risk management skills can be expected to be strengthened with a view to improving the decisionmaking process and ensuring effective control over all parts of the group to obtain an accurate picture of exposure to risk at the group level ${ }^{1}$. The regulator also expects arrangements for internal solidarity to be put in place to ensure a proper resolution if one component entity undergoes financial stress. Establishing such mechanisms also has the effect of reinforcing risk governance. Two principal types of arrangement are currently observable:

\section{Simple systems of guarantee and solidarity}

This system was in place in two of our sample cooperative groups, and broadly described in their reference documents. Its aim is to guarantee the liquidity and solvency of the group and affiliated institutions so as, if need be, to organize the financial solidarity within different groups of entities or

\footnotetext{
${ }^{1}$ Several studies link the existence of a risk-management arrangement with reduced exposure to risk. See, e.g., Aebi et al. (2012), Ellul et al. (2013).
} 
brands $^{2}$ before looking at overall solidarity between the entities. In the BPCE Group, the central organization is responsible for taking all necessary steps to guarantee solvency for the group as well each of the entities or brands, particularly by implementing appropriate internal solidarity mechanisms for the group and creating a guarantee fund common to all the brands whose operational rules it determines, and the modalities for releasing supplementary funds from two existing networks, as well as the contributions of affiliated institutions for its provision and reconstitution.

All legal entities in a group will come to the aid of beneficiaries in the case of a temporary liquidity situation (guarantee of liquidity) or to avoid or manage situations of financial defaulting (guarantee of solvency). The solidarity mechanism is inbuilt in the BPCE Group and does not constitute a guarantee that can be triggered by a third party, although French supervisory banking authorities might demand that the mechanism be brought into action if circumstances demand.

The main limit to this kind of device is that it cannot benefit from a reduction in prudential demands, unlike mechanisms of the IPS kind described below. For the regulator, the question lies in his governance with consequences in terms of reactivity and decision-making in a crisis situation (the organization holding authority).

\section{The institutional protection scheme (IPS)}

The Capital Requirements Regulation (CRR) defines an IPS as an arrangement, contracted or as framed by law, that protects the establishments that compose it and, in particular, guarantees their liquidity and their solvency to avoid bankruptcy, should the case arise (article 113, paragraph 7 of the CRR, first phrase). The competent authorities can, in accordance with the conditions laid down in the CRR, exempt the members of an IPS from some of the prudential requirements or grant them exemptions. Currently, IPSs are recognized for the purposes of a CRR in three countries participating in the single supervisory mechanism (SSM): Germany, Austria and Spain.

According to the ECB, in absolute terms, the importance of the IPS is considerable, given that $50 \%$ of credit establishments in the eurozone belong to an IPS, which represents about $10 \%$ of the total financial assets of the zone. In most cases, big and not so big establishments that are subject to surveillance by the ECB are members of the same IPS. Because of the high degree of autonomy and independence of establishments, in certain cases the ECB considers that although this mechanism guarantees the liquidity and solvency of its members, it is not the same as a consolidated banking group.

In such a framework, the characteristics of the IPS evaluated by the ECB will mainly affect:

- the absence of obstacles to the transfer of funds between units;

- the rapidity of transfers;

- the absence of serious difficulties in management matters;

- the absence of serious problems in corporate governance in connection with members

- the decision-making process relative to the support measures allowing a solution to be found in due course.

\footnotetext{
2 In many cooperative groups there are several different brands. The entities belonging to the same brand are first solid among themselves before looking for solidarity between the brands and other affiliated entities.
} 
The topic of governance is therefore central and concrete situations need to be evaluated within the cooperative groups concerned, which may not depend on ECB criteria.

\subsection{2 - Does a risk appetite framework really push towards centralization?}

In another study conducted by the Chair, with Stephane Albert (2016), we analyzed the effect of this new regulatory context on the governance of three big cooperative banks in Europe.

In conformity with prudential regulations, the various groups studied have set up methodologies allowing them to frame their overall appetite for risk. The methodologies were applied on a large scale (the units making up the groups) and/or on a consolidated basis. The definition of the appetite for risk is stated according to several leading indicators (LI) covering capitalization and liquidity risk but also, for three of them, profitability risk (earnings volatility). The appetite for risk is thus spread in a granular configuration according to the various risks. The limits ensure consistency between day-today management (decisions) and management aims. The $\mathrm{LI}$ and specific limits constitute the risk management strategy. The specific limits apply right up to the consolidated level for three of the four groups, which lead us to suppose that they are themselves derived from consolidated leading indicators (CLI). This is in fact the case and three of the groups have defined their appetite for risk on a consolidated basis. This supposes a certain degree of centralization or at least of coordination when the consolidated levels are fixed.

Our analyses have revealed a growing role for the central body but its responsibilities vary enormously from one group to another. As in 2014, our specific study on risk governance highlights three models of risk governance.

The totally centralized model where supervision on a consolidated basis is more than just a starting point for the management cycle and the use of a CLI places the supervision at the heart of a risk management cycle. This management of risk up to group level does not necessarily result in authority over the day-to-day management of local risks. We observed such authority in one coop whose governance is resolutely centralized and whose local units are no longer subject to prudential requirements.

Despite the existence of a CLI, a lesser degree of day-to-day authority is observed in some cases (according to different intensities). This is also manifested by an absence of hierarchical link between the central unit and the monitoring (and analysis) functions of local risks. However, the central unit does have a functional and/or normative authority. We propose that the model operated by these kinds of groups is "shared risk governance model".

In one case, the coop bank maintains clearly more decentralized day-to-day management. Its IPStype solidarity mechanism nevertheless has teams monitoring the capitalization of all the units, and a group risk committee. The IPS also ensures the deployment of consistent methodologies at group level. The units are autonomous when it comes to day-to-day strategy and management. This model is "decentralized" but not totally because it is also "monitored". The role of the IPS can be compared to that of the supervisory authorities. We see the existence of an IPS with a defined authority (a capacity for preventive intervention) as constituting an initial level of centralization, at least for the integration of the management of risks. 
Finally, we raise the question of the role of governance, executive directors and executive boards in the internal control system that establishments set up (Lamarque and Karfoul, 2009). The preoccupation with the quality of governance does not concern monitoring but does reinforce its significance and the contribution it makes to strategic decision making and fixing risk-taking levels. The movement is the logical consequence of criticisms made by the authorities about the passivity of governance bodies (boards of directors and supervisory boards) when it comes to controlling the risk taking of the establishments they supervise. In July 2015 the BCBS published its latest recommendations on the principles of business governance for the banking sector.

Here again, we find concerns about the composition and qualifications of board members.

Everything therefore converges to increase the level of expertise of governance bodies, enabling them to fulfill their function of management decision oversight, challenge them, and assume their responsibilities in matters of strategic choices and risk policy.

These changes also result in stricter supervisory control of the quality of governance and the possible reconsideration of certain administrative appointees. We reach a kind of certification of governingbody members ascertaining whether they actually have the ability to carry out their functions.

The profiling and selection of board members are directly affected by this new regulatory context. This poses several challenges to the way that board members are recruited. Even the term "recruitment" may seem incongruous, seeing that board members are elected at the shareholders' general meeting (for a bank with share capital) or by members' general assembly (in the case of cooperative banks). Changing the way board members are appointed is not currently under consideration. So-called independent administrators must also be elected by the general assembly. However, what clearly appears from these "fit and proper" principles gradually being adopted is that candidates who are proposed for election must respect these expectations.

For cooperative banks, the election of financially experienced board members is still problematical. As cooperatives with customers, these banks have a governance system that means clients can be elected to governing bodies. In this system, financial expertise comes second to members' interests. The implementation of these principles has already had consequences in that certain elected heads of executive boards on cooperative banks have had to stand down from their post as executive director. But the most difficult task will be to find candidates who have the required skills to conform to the new principles. For these actors it is a question of reflecting upon new devices that maintain both the specificity of the model and the capacity to constitute a board that brings together all the skills needed for it to be considered as collectively efficient.

Moreover, all the banks are going to implement training programs for their administrators to maintain and increase the skills base. However, seeing how complex the principles of banking management and associated regulations are, it is not obvious that the training currently being put together will be sufficient to attain the level desired. Besides this attempt at conformity, which seems to worry those concerned, the efficiency of governing bodies and the quality of decisionmaking is now recognized as a real competitive advantage. Many companies have embarked upon programs to increase their efficiency and the quality of their contribution. 


\subsection{The challenges for coop governance model under new regulatory change}

At various moments in of this chapter we mentioned the changes to certain governance principles and methods needed to comply with new requirements. For many supporters of the coop model, these are effectively threats to the basic historic principles of what constitutes a coop. Our feeling is that the regulators won't modify their policy of building regulations for all banks, and it is very hard to apply the frequently mentioned principle of proportionality (see chapter 8 ) to say that regulation can be adapted to coops. Here, we look at some proposals aiming to comply with regulatory issues, maintain the cooperative DNA and also increase the level of responsibility of governance bodies.

Everything therefore converges to increase the level of expertise of governance bodies, enabling them to carry out their task of monitoring management decisions under good conditions, challenge them but also assume their responsibilities in matters of strategic choices and risk policy. But these changes have an impact on various aspects of coops' specific governance systems.

Leaving aside the issue of gender parity, the question of board structure is vital if they are to be in a position to assume the new obligations and responsibilities that the regulator has reinforced. Also, it is necessary that the practices of naming and electing administrators should comply with the legal principles of common law or the more specific law governing cooperatives.

In line with these new functions, the constitution of boards is also the subject of very specific obligations, far removed from current practices in cooperative banks. While the regulators' expectations of the skills and experience of board members are logical, enabling ever more complex tasks to be carried out, beyond simple monitoring, the development of these functions for governance bodies is the focus of many expectations that could conflict with cooperative principles:

- The presence of a "sufficient number" of independent administrators: in listed companies this is a legal requirement requiring a minimum of one third of the board members. The issue of "the right proportion" of board members and their independence is a regular topic of debate and even controversy. The codes of good practice may list objective criteria but they are not necessarily enough to ensure the requisite independence of spirit and judgment to challenge managers constructively, yet another quality expected of an administrator by the same regulators. Moreover, candidates are usually put forward for election by the executive management during the general assembly and their independence vis-à-vis the GA may be doubtful. Besides, many scientific papers have shown the limits of the independence criterion and there is no obvious relation between the percentage of administrators on a board and the company's level of performance.

The principle of the independent member of the board has been totally rejected by cooperative banks. Their boards are made up of client members democratically elected at different levels of governance (local, possibly regional and national). At times, non-voting members may sit on the board, having been elected by a general assembly (as in Caisses d'Epargne, for example). The argument often mobilized when rejecting the presence of this kind of board member is based on the limits of independence, briefly discussed above. To this is often added the argument of the genuine independence of members through their democratic election, which would naturally confer this status and even this duty on them. Thus the status quo is perfectly suitable and the renewing of administrators continues to follow the usual pattern. 
This being so, it must be borne in mind that no regulator nor any expert in governance would consider the boards independent on account of the status of all the elected members as customers of the bank. Giving decision-making power to a bank's own clients, the very principle of a clients' cooperative, can act as a counterweight to managerial proposals but may not necessarily act in the general interest of the cooperative. So, independence of judgment is there to ensure that the general interest is preserved as well as the continued existence and development of the cooperative and to prevent its acting only for the few.

The constitution of "balanced" boards in terms of skills and experience: here, the argument is to consider the boards as collective structures with complementary skills where there is collective responsibility for decisions. This also argues in favor of diversity of skills. The members of specialized committees (audit, risk, remuneration) arising from different sectors of activity need more specific skills pertinent to these topics. Having only specialists in banking and insurance or in financial markets on a board is not desirable nor is it explicitly desired by the regulators; in any event, it would not guarantee the pertinence of decisions. However, regulators expect both "a rigorous process of identification, evaluation and selection of future administrators" and "planning for the appropriate succession of board members" (BCBS on bank corporate governance, July 2015). The idea is therefore to set up boards that bring together all the skills and experiences pertinent to the governance of a financial cooperative. The Basel documents include a long, non-exhaustive inventory: capital markets, financial analysis, factors of financial stability, financial reporting, information technologies, strategic planning, risk management, remuneration, regulations, business governance and managerial skills. Since this concerns cooperatives, we may add cooperative values and social commitment, to name just the most obvious two.

It is not easy for coops to comply with this expectation due to the "recruitment" of board members through elective systems and not specifically based on individual and collective capabilities.

Beyond the composition of boards and the profile of elected members, there is the question of the work that boards do, their efficiency in the monitoring of decisions and above all their capacity to contribute to and make decisions. Moreover, in the most critical cases, supervisors pay attention to the speed of response when taking the necessary steps.

After the professionalization of board members, we move onto the professionalization of how the board functions. The role of the chairperson is of course vital to running discussions, organizing members' turns to speak, and respecting everyone's contribution to the debate. Setting up explicit procedures on how things are organized (agenda, delivery times for the receipt of documents, structure of documents) is naturally one aspect of this work.

We would like to emphasize two more problematical issues in the context of financial cooperatives:

- The time devoted to tasks, and the remuneration of board members: we class these two subjects together because they are closely linked. Historically speaking, being a board member in a cooperative was akin to volunteering, which presupposes that the individual concerned received no compensation for taking part in any tasks or meetings. In the past, administrators gave up their time to serve the cooperative. In the context of financial cooperatives, especially those subject to the fullest regulatory framework because of their size, this voluntary contribution was clearly questionable. The regulations applying to 
cooperatives contain specific reminders about the impossibility of offering attendance fees, preferring much lower compensatory allowances. But regulation strictly concerning banks implies more and more formal meetings, working groups or seminars, reading several hundred pages before meetings, and that does not count the time given over to training. Board members with busy professional lives elsewhere and skills in various subjects of interest to the board can meet the demands of volunteering. So there is a profound contradiction between neutral commitment, the demands of being involved and the responsibility and level of expertise demanded of board members today. We are well aware that this is a key dimension in the cooperative model and a sensitive point in terms of governance, but the question of board member compensation must be raised and must be aligned with the new requirements for supervisors.

- Regular evaluation of board members: given our insistence on a proposal for remuneration that effectively matches the time demanded by administrator tasks and new responsibilities, we propose the implementation of regular evaluation processes rather than waiting for statutory renewal dates before calling the presence of a board member into question. Revocability must not simply be linked to absenteeism or to questions of honorability, but to the reality of an individual's contribution to the work of the board. Defining the profiles and specific skills required of one member or another will make this evaluation more objective.

Are these initial proposals likely to improve the quality of decisions taken by the boards? The answer can only be provided after a scientific study of the many establishments that have implemented such an instrument. For us, the main goal is to start rolling these developments out, allowing boards to take real responsibility for decision-making processes as the regulations stipulate. If we want the chairman of the board to always be considered a responsible leader, if we want boards to be collectively responsible for certain decisions, and if we want to identify the individual responsibility of certain members then, in our estimation, the tools currently available do not allow all this. The growing complexity of the subjects handled, documents provided and decisions to be made continue to reinforce the power of managers despite all efforts made to train board members.

\section{Conclusion}

Ultimately, the fundamental question cooperative banks must ask themselves is how do they want to use their board and governance structure. Are they really strategic for the development and the transformation of the cooperative banking business model? Or are they simply a place to collect feedback customer needs and feelings? If you answer yes to the first question you must adapt your governance model not only to the requirements of regulators but also to changes within the banking industry (digital, power of some communities, reputational risk, operational risk...) and build a governance model capable of supporting managers and not just controlling them. If you answer yes to the second question, then it is better to leave all decision-making responsibility in the managers' hands and let the boards play a role of go-between for client-members' concerns, guaranteeing the fundamental principles of a cooperative.

Our final thoughts lead us to envisage a proposal that aims both to guarantee respect for the basic values of cooperatives and the demands for the professionalization of banks' governing bodies. We propose the creation of a dual governance structure with two types of board: 
- A board of expert members set up along the classic lines of a company in terms of the number of independent members with the profiles and skills required. If ever professional certification for bank administrators became the norm in this sector, there would be no conflict with the rules and principles of its status as a cooperative. The limits of its responsibility would be clearly defined in terms of control and the scope of propositions to be made in the domain of strategy, risk management or any other topic defined as its prerogative. It would be necessary to establish clearly the subjects on which it would have definitive decision-making power and those where it would have just a simple power of proposal.

- A cooperative board made up of client-member administrators: this would guarantee that cooperative values and principles are respected before any definitive decisions are made. It would allow client-members' concerns to be taken into account, as boards in their current state already do. The board's role and extent of its powers in decision-making processes would also need to be defined, depending on the topic in question.

We believe that such an instrument will ensure respect for both technical demands and cooperative principles, and could give governance bodies some genuine weight in decision-making processes, which, in our opinion, is the only way to make them really responsible.

We do not deny there would be difficulties in the operational implementation of such an instrument but we note some experiments in which this double logic and joint participation in decision-making processes already exist. In many cooperative banks there are special committees, besides the board of directors, which are consulted over decisions or associated with them. We have also noted that in banks built up around a strong values-based identity, such as Islamic banks, the coexistence of a board of directors and a Sharia board has real controlling power over the decisions made.

Either way, the time has come to start a real transformation process for governance structure and governance management involving a majority of members in the decision-making processes and cooperative life.

\section{References}

Aebi V., Sabato G., Schmid M. (2012): "Risk management, corporate governance, and bank performance in the financial crisis", Journal of Banking \& Finance, vol. 36, issue 12, 3213-3226. Available on http://www.isihome.ir/freearticle/ISIHome.ir-24018.pdf

Albert S., Lamarque E. (2016): "The impact of financial regulation on policy and risk management in financial cooperatives", Study for the $3^{\text {rd }}$ international summit on Cooperatives, Quebec. Available on https://www.sommetinter.coop/sites/default/files/etude/files/iae-etude-en.pdf

Basel Committee on Banking Supervision (2015): Guidelines Corporate Governance Principles for banks, July.

Birchall J. (2017): "The governance of large cooperative businesses", Coop UK. Available on https://www.uk.coop/sites/default/files/uploads/attachments/governance-

report_2017_final_web.pdf 
Deville A., Lamarque E. (2014): "Identification and valuation of cooperative banking models", Study for the $2^{\text {nd }}$ international summit on Cooperatives, Quebec.

Deville A., Lamarque E. (2016): “Diversity of cooperative bank governance models questioning by regulation: An international qualitative research", French Association of Accounting, Clermont Ferrand.

Di Salvo, R. (2002): "La governance des systèmes bancaires mutualistes et coopératifs en Europe", Revue d'économie financière, no. 67: 165-179.

Ellul et al (2013): "Stronger Risk Controls, Lower Risk: Evidence from U.S. Bank Holding Companies", Journal of Finance

European Banking Authority (2012): "Guidelines on the assessment of the suitability of members of the management body and key function holders", June

"Joint ESMA and EBA Guidelines on the assessment of the suitability of members of the management body and key function holders under directive 2013/36/EU and Directive 2014/65/EU"

European Banking Authority (2016): Consultation document on Guidelines on internal governance, October

European Central Bank (2017): Guide to Fit and Proper Assessment, May.

Karfoul H., Lamarque E. (2009): “Gouvernance des banques et maîtrise des risques", Revue Française de Gouvernance d’Entreprise, n5, Septembre 2009

Lamarque E. (2017): "The Impact of Basel III on the Operations of Retail Banks", in Douady, R. (Ed), Goulet, C. (Ed), Pradier, P. (Ed), Financial Regulation in the EU, Palgrave MacMillan

Ory, J.N., Gurtner E., Jaeger M. (2006): "Les enjeux des mutations récentes des groupes bancaires coopératifs français", Revue internationale de l'économie, No. 301.

Ory J.N, De Serres A., Jaeger M. (2012): “Comment résister à l'effet de normalisation: le défi des banques coopératives", Revue des Sciences de Gestion, n²58, novembre 